\title{
Usage of glass ionomer cements for reconstructions in the head region
}

\author{
Andreeva R. \\ Department of Pediatric dentistry, Faculty of Dental Medicine, \\ Medical University Varna Bulgaria
}

\begin{abstract}
Glass ionomer cements are a two-component hybrid material, consisting of inorganic glass particles, surrounded by an insoluble hydrogel matrix. They are a group of materials based on the acid/ base reaction between poly (alkenoic) acid and an ion-leachable silicate glass. Their biocompatibility, osteoconductive behavior, and ability to bond to bone and metals have generated interest in the material for medical applications. GIC are widely used in dental medicine as an obturation material in primary teeth for treatment and prophylaxis of dental caries, because they have the ability to create a physicochemical bond to tooth structure and to release fluoride. They are currently frequently used in otological and neuro-otological surgery. Apart from ossicular chain reconstruction, they are used for repair of tegmen defects, outer ear canal reconstruction, mastoid obli teration, and stabilization of some hearing prostheses.
\end{abstract}

\section{Introduction}

Glass ionomer cements are acid-based materials, based on the reaction product of weak polymeric aicds used in combination with powdered glasses of basic character. Setting occurs in concentrated solutions in water and the final structure contains a substantial amount of unreacted glass which acts as filler to reinforce the set cement. This hybrid material has been successfully used as bone cements, for incudostapedial joint, the incus augmentation, as well as for the fixation of stapes prostheses [2]. Ossicular chain reconstruction with ionomeric cement is easy to perform, presents less risk of damage to the stapes and cochlea, requires less extensive surgery and does not exclude other surgical methods in cases of reoperation [19]. Glass ionomer cement (GIC) materials can bond chemically to both dentin and enamel with dynamic covalent bonds, allowing the formation of a new bond if one breaks. Bond strength to dentin can be increased by pre-treating the dentin with conditioning agents that remove the smear layer. In addition, GIC materials offer biocompatibility, although these biological properties are product specific. GICs also offer fluoride uptake and release. The fluoride gradually leaches from the set cement in the first few months after placement but can be recharged from the oral environment and repeats the leaching process. GIC restorations therefore act as a fluoride reservoir. Among the disadvantages of GICs are relatively 
poor compressive and tensile strength, surface roughness, relatively poor color stability, and poor resistance to wear. When used as 2-surface (class II) restorations in primary molars, conventional GICs perform poorly. [5]

\section{Aim}

To determine the decrease of the air bone gap between the incus long process and the stapes, after the use of glass-ionomer cement for reconstruction and to establish the biocompatibility and caries preventive effect of GIC in primary teeth restorations.

\section{Materials and methods}

The study includes 20 patients with incus long process defects, which were caused by chronic otitis media and repaired with glass ionomer cement. The audiological tests (air conduction thresholds, bone conductive thresholds, air bone gaps) obtained preoperatively and one year after surgery were compared. Preoperative and postoperative air bone gap differences were estimated to determine hearing gain. Bone cement was used when the length of incus long arm defect was $3 \mathrm{~mm}$ at maximum. The two components of the GIC are mixed in sterile conditions and the mixture is applied between the defective incus long process and the head of the stapes, forming an incudostapedial bridge. The GIC was also used as a restorative material in primary teeth for 150 patients in all cavity types for children between 3-12 years. The restorations and the adjacent surfaces were followed until exfoliation/extraction of the teeth, repair/replacement of restorations or operative treatment of adjacent surfaces. Survival analyses supplied with multivariate analyses were performed to assess the influence of different factors on the longevity of restorations, the hermeticity of the material and the caries preventive effect of the fluoride in the GIC.

\section{Results}

Pre- and postoperative audiometry reveals significant improvements in mean air-conduction threshold and ABG. [24] The evaluation of the repair of the defects of the incus long process with ionomer cements indicates a satisfactory physiological ossicular chain reconstruction consisting in $\mathrm{ABG} \leq 10 \mathrm{~dB}$ in $40 \%$ of the patients. Incudostapedial rebridging ossiculoplasty with polymalein- ate glass ionomer bone cement is a cost-effective and safe procedure that yields good hearing results in selected patients. GIC positive contributions are as follows:

1. Scar tissue connecting the ossicles in slight defects of the incudostapedial joint can be stabilised by glass-ionomer cement leading to a reasonable sound transmission.

2. If the incus has to be removed in case of a more serious defect, the columella can be properly fixed to the stapes by means of glass-ionomer cement without the risk of scar-induced lateralisation.

3 . The fixation of the stapes prosthesis' wire loop to the incus can be effectively achieved by glassionomer cement. As a result mean air conduction and air bone gaps decreased significantly one year after surgery when compared to the preoperative values ( $p<0.001$ for both). Mean hearing gain was $20.33 \pm 6.36 \mathrm{~dB}$ one year after surgery. The postoperative air-bone gap was less than $20 \mathrm{~dB}$ in $83.3 \%$.

Fluoride released from glass ionomer cements (GICs) is capable of preventing caries lesions. For occlusoproximal analysis, GIC was associated significantly with better ability to prevent caries lesions (odds ratio, 1.7; 95\% confidence interval, 1.2-2.5). After 12 months of follow-up, the restorations were considered clinically successful in $89.3 \%$ of cases and radiographically successful in $80.5 \%$ of cases. GIC exhibit significantly lower values of secondary carious lesions (SCL) than composite restorations (SCL: risk difference 0.06 $\left.[0.02,0.10], \mathrm{p}=0.008, \mathrm{I}^{2}=0 \%\right)$. The materials presented similar performance $(\mathrm{p}>0.05)$ regarding the overall effect, as well as for marginal discoloration, marginal adaptation and anatomical form. The superiority of GIC was maintained when resin-modified GIC and rubber dam isolation were analyzed separately.

\section{Discussion}

Ossicular chain reconstruction with ionomeric cement is recommended, as the procedure is easy to perform, presents less risk of damage to the stapes and cochlea, requires less extensive surgery and does not exclude other surgical methods in cases of reoperation. [19] The hybrid bone substitute ionomeric cement achieves a stable and durable space-free bond to adjacent bone during hardening. Entirely hardened ionomeric cement as an ossicular prosthesis shows good biocompatibility with out- 
standing functional results. [21] GIC is a simple, cost-effective method which gives definite good postoperative hearing improvement in pediatric patients. Other advantages are more physiological continuity between the incus and stapes, technically easier application, nonextrusion. ABG closure is statistically significant $(\mathrm{p}<0,01)$ [6].

Studies have shown that glass ionomer bases and liners exhibit less marginal microleakage thereby preventing bacterial penetration. [16, 20] Fluoride is released from glass ionomer cement by dissolution and diffusion. Glass ionomers have demonstrated the inhibition of secondary caries formation. $[9,14,17,18]$ The fluoride released is taken up by both the enamel and dentin adjacent to the material. [7, 12, 13, 25] This fluoride aids in creating an inhibition zone that is not susceptible to demineralization, when compared with areas adjacent to non-fluoride-releasing materials. [8, 15] Preparations of glass ionomer cements are available in various shades that can be used for anterior restorations. [1, 4] The use of glass ionomer for anterior restorations is limited to class III and class $\mathrm{V}$ preparations. The low fracture resistance and strength of mechanical bonding to enamel make its use impractical for class IV restorations. Retention of glass ionomer restorations in the restoration of class $\mathrm{V}$ preparations, where the gingival margin is not in enamel, may demonstrate favorable retention when restored with a glass ionomer rather than a resin-based composite. The fluoride release from glass ionomer restorations has been shown to inhibit the development of secondary caries. [10, $11,26,27]$ The anti-cariogenic biofilm activity of GICs is closely correlated with their fluoride release rate during biofilm formation.

Because new caries lesions in the margins of restorations are the main reason for failure and replacement of restorations in primary teeth, it is important to know whether there is a benefit in using GICs in both occlusal and occlusoproximal cavities. GIC are the material of choice for restorations in primary teeth and especially for children with special needs, as the material is easy to use, has a fast setting time and manages to achieve hermeticity in situations, when isolation is hard. Metal particles have been added to glass ionomer cements to increase their strength and wear resistance for posterior restorations, as their main concern is its susceptibility to fracture and wear. Investigations have demonstrated the clinical success of resin-modified glass ionomer cement as a posterior restorative material in the primary dentition. $[3,10,23]$

\section{Conclusion}

GIC is easy to use, has great biocompatibility and is a cost-effective material, which finds use in multiple reconstructive procedures.

\section{Bibliography}

1. Berg JH. Glass ionomer cements. Pediatr Dent. 2002; 24: 430-438.

2. Chen D.A, Arriaga M.A, Technical refinements and precautions during ionomeric cement reconstruction of incus erosion during revision stapedectomy. Laryngoscope. 2003; 113(5): 848-852.

3. Croll TP, Bar Zion Y, Segura A, et al. Clinical performance of resin-modified glass ionomer cement restorations in primary teeth: a retrospective evaluation. J Am Dent Assoc. 2001; 132: 1110-1116.

4. Croll TP, Nicholson JW. Glass ionomer cements in pediatric dentistry: review of the literature. Pediatr Dent. 2002; 24: 423-429.

5. Dental Abstracts, Volume 65, Issue 1, January-February 2020, Pages 54-57.

6. Dere H, Ozdogan F, Ozcan KM, Selcuk A, Ozcan I, Gokturk G, Comparison of glass ionomer cement and incus interposition in reconstruction of incus long process defects - Eur Arch Otorhinolaryngol., 268, 2011, No 11, 1565-1568.

7. Diaz-Arnold AM, Holmes DC, Wistrom DW, et al. Short-term fluoride release/uptake of glass ionomer restoratives. Dent Mater. 1995; 11: 96-101.

8. Donly KJ. Enamel and dentin demineralization inhibition of fluoridereleasing materials. Am J Dent. 1994; 7: 275-278

9. Donly KJ, Ingram C. An in vitro caries inhibition of photopolymerized glass ionomer liners. ASDC J Dent Child. 1997; 64: 128-130.

10. Donly KJ, Segura A, Kanellis M, et al. Clinical performance and caries inhibition of resin-modified glass ionomer cement and amalgam restorations. J Am Dent Assoc. 1999;130: 1459-1466.

11. Ewoldsen H, Herwig L. Decay-inhibiting restorative materials: past and present. Compend Contin Educ Dent. 1998; 19: 981-992.

12. Forsten L. Fluoride release and uptake by glass ionomers and related materials and its clinical effect. Biomaterials. 1998; 19: 503-508.

13. Forsten L. Resin-modified glass ionomer cements: fluoride release and uptake. Acta Odontol Scand. 1995; 53: 222-225.

14. Garcia-Godoy F, Jensen ME. Artificial recurrent caries in glass ionomer-lined amalgam restorations. Am J Dent. 1990; 3: 89-93.

15. Griffin F, Donly KJ, Erickson RC. Caries inhibition of three fluoride-releasing liners. Am J Dent. 1992; 5: $293-295$.

16. Heys RJ, Fitzgerald M. Microleakage of three cement bases. J Dent Res. 1991; 70: 55-58.

17. Hicks MJ, Flaitz CM, Silverstone LM. Secondary caries formation in vitro around glass ionomer restoration. Quintessence Int. 1986; 17: 527-532. 
18. Jensen ME, Wefel JS, Hammesfahr PD. Fluoride-releasing liners: in vitro recurrent caries. Gen Dent. 1991; 39: 12-17.

19. Kjeldsen M, Grontved A.M, Tympanoplasty with ionomeric cement. Acta Otolaryngol Suppl. 2000; 543: 130-131.

20. Manders CA, Garcia-Godoy F, Barnwell GM. Effect of a copal varnish, ZOE or glass ionomer cement bases on microleakage of amalgam restorations. Am J Dent. 1990; 3: 63-66.

21. Milkov M, History of prostheses for ossiculoplasty made of different kinds of biomaterials - Otorhinolaryngologiya, 6, 2002, No 3, 12-15.

22. Milkov M, Nedev P, Vicheva D, Zenev I, Kunev K, Rouev P, Matev D, Reconstruction of the ossicular chain with prostheses made of ceromer - In 5th European Congress of Oto-Rhino-Laryngology, Head and Neck surgery. Rodos-Kos, 11 - 16.IX.2004. Abstract book, p. 140.

23. Mjцr IA, Dahl JE, Moorhead JE. Placement and replacement of restorations in primary teeth. Acta Odontol Scand. 2002; 60: 25-28.

24. Serin GM, Cam B, Derinsu U, Sari M, Iar Batman. Incus augmentation with glass ionomer cement in primary and revision stapes surgery - Ear Nose Throat J., 89, 2010, No 12, 589-593.

25. Skartveit L, Tveit AB, Twtdal B, et al. In vivo fluoride uptake in enamel and dentin from fluoride-containing materials. ASDC J Dent Child. 1990; 58: 97-100.

26. Souto M, Donly KJ. Caries inhibition of glass ionomers. Am J Dent. 1994; 7: 122-124.

27. Ten Cate JM, Van Duinen RN. Hypermineralization of dentinal lesions adjacent to glass-ionomer cement restorations. J Dent Res. 1995; 74: $1266-1271$.

28. Milkov M, Nedev P, Vicheva D, Zenev I, Kunev K, Rouev P, Marev D. Reconstruciion of the ossicular cirain with prosthesis made of ceromer. 5th European Congress of Oto-Rhino-Laryngology Head and Neck Surgery, 11 - 16.X.2004, Rodos-Kos, Hellas.

29. Rouev P, Milkov M, Nedev P, Dimov P, Marev D. Ossicular Rekonstruktion mit bulgarischer Prothese von Ceromer. 76. Jahresversamlung DGHNOKHC, Erfurt, 4 - 8.05.2005.

30. Milkov M, Nedev P, Zenev I, Kunev K, Rouev P, Marev D. One Year Experience at the Restoration of the Auditory Chain with Prosthesis of Ceromer. Pro Otology 2004; 4(I): 47-48.

31. Руев П, Едрев Г., Милков М. Осикуларна реконструкция с протези от Ceromer. Международен бюлетин по оториноларингология $2005 ; 1(2): 21-6$

32. Milkov M. Dental application applications of hydroxyapatite cement - a promising challenge. Scripta Scientifica Medica, MU - Varna, Vol. 42(2), 2010, pp. 105-108, ISSN 0582-3250. 